\title{
Environmental Physical and Perceived Quality in Hospice
}

(C) The Author(s) 2021

Article reuse guidelines: sagepub.com/journals-permissions DOI: $10.1177 / 19375867211028160$ journals.sagepub.com/home/her

(SAGE

\author{
Tiziana Ferrante, PhD, M.Arch' and Teresa Villani, PhD, M.Arch'
}

\begin{abstract}
Objectives: This study presents the application of post-occupancy evaluations (POEs) methodologies to facilities for palliative-hospice care, in order to directly assess the physical-spatial qualities better suited for the specific psychological needs of "fragile" users and to ensure better architectural quality in new projects and in renovation measures. Background: In international literature, there are few studies concerning the application of POEs to hospice, assessing the impact of individual environmental factors on users' psychoemotional reactions. The set of elements that patients and their families perceive as important, defining the architectural quality of a hospice, has not been sufficiently investigated yet. Method: Therefore, a POE was performed on a sample of hospice in Italy, by preparing a self-filled questionnaire addressing patients and relatives. Indicators of perceived physical-spatial humanization, which were validated for hospital facilities (perceived hospital environment quality indicators), were used for the assessment then implemented and harmonized in relation to hospice facilities features. Results: The study revealed the indicators of architectural quality most valued by users, whose reliability was then verified, along with their average quality, by highlighting recurring shortcomings. The global quality was found to be generally high. Below-average scores were found for indicators on usability, acoustic comfort of outdoors, visual and acoustic comfort of shared indoor spaces, and artificial lighting in the recovery room. Conclusion: The study generated new knowledge on hospice and confirmed the efficacy of POEs as a tool both for purchasers and designers. Indeed, the first results of this study allow to recalibrate building programs, revisiting layouts, and elaborating appropriate technical solutions.
\end{abstract}

\section{Keywords}

post-occupancy evaluation, hospice design, healthcare design, evidence-based design

Post-occupancy evaluation (POE) is a systematic process of evaluating the performance of buildings after they have been constructed and occupied for a period (Preiser et al., 1988; Preiser, 1995). Through flexible procedures and tools, we can measure the satisfaction of the building users and occupancy rate through time (Harvey, 1984). This helps to deduce answers from building functioning and to test the effectiveness of design choices in relation to the space usage.

Within the building process, we can also apply POE to test the performance level that users require through time, in terms of effectiveness and efficiency. These methodologies differ from the ordinary design practice in the building's

\footnotetext{
'Department of Planning, Design, and Technology of Architecture, Sapienza University of Rome, Italy

\section{Corresponding Author:}

Teresa Villani, Department of Planning, Design, and Technology of Architecture, Sapienza University of Rome, via Flaminia 70, Rome, 00196 , Italy.

Email: teresa.villani@uniromal.it
} 
intended use, the qualities surveyed, and the users of reference and are presently among the most accredited evaluation methodologies (Ferrante, 2013). Once we select the proper ex post evaluation target and analysis level (indicative, investigative, and diagnostic), we also need to select those aspects that are particularly significant. The evaluation emphasis is on technology (thermohygrometric, acoustic, visual comfort, etc.), functionality (organization of spaces, proper furnishings, wayfinding, etc.), and management (maintenance of technical elements and finishes, hygiene, systems inspections, etc.). However, we also consider users' feedback relatively to space utilization, in terms of perceptible factors (privacy, overall liking of the hospice, impact on socialization, etc.).

Therefore, survey techniques are extremely variable and there is no unique method to conduct a POE. It depends on the assessment goal, on used quantitative and qualitative analysis method through a multidisciplinary approach. We can detect quantitative and physical qualities more easily than nonphysical qualities. Users can perceive these through sensations, emotions, feelings, and suggestions, thus more subjectively (Vischer, 2008).

Various investigation techniques sometimesas we report below for the POE applied to palliative-hospice-have led to relevant user experience factors. These include users' conditions, habits, and space use. Thus, we can check how the "ex ante" predictive design model complies with the specific building requirements to the largest extent. Prerequisites are then essential for building performance evaluation that includes multidisciplinary contributions. This can lead to a strongly interdisciplinary and user-centered design approach. POE methodologies build on collaboration and dialogue between various expertise to extend knowledge for reducing the gap between design and users' perception.

The output of a POE can be a milestone for future implementation that highlight critical factors involving users and built environment. The assessment of design impact on healthcare environments (Alvaro \& Atkinson, 2013) can come along with new information and knowledge. We can use it to redesign healthcare facilities and upgrade design criteria of similar facilities to changing care processes. Through extensive POE case studies, a relevance of different indoor qualities is emerging (Fisk, 2002). This allows experts to identify generalizable design criteria.

POE is widely spread and recognized in healthcare design in terms of human-centered design impact (Millet et al., 2018) and evidence-based design methodology founded on Vischer (2009). A large international scientific literature established the relation between the hospital design of the hospital and multifaceted impact on patients and staff (Ulrich et al., 2008; Ulrich et al., 2010). However, there are still few experiences as to hospices (Kader, 2016, 2017). Hospices are relatively recent social-health facilities for palliative care (Rigby, 2008; Rigby, Payne \& Froggatt, 2010). In Italy, the residential palliative care hospices (RPCHs) were established in 1999 as facilities for terminal palliative care patients of different age groups. The Italian technical regulations are in the Prime Minister Decree (DPCM) January 20, 2000. All the hospices established before that date were with no specific indications of design quality. While hospices were already being built internationally with single rooms (Worpole, 2009), in Italy, some hospices built before 2000 still have double rooms and few community areas that would need deep refurbishment.

Conducting a POE in hospices and RPCHs makes interviews and questionnaires very hard because of patients' conditions. However, considerable improvements are still needed for the evaluation of the psychosocial and emotional well-being of family members and caregivers. As a result, hospices have been much less investigated on POE than in other healthcare settings. Some more recent research on design is significant in understanding the relationship between palliative care and the quality of palliative care spaces (Zadeh \& Eshelman, 2019). Some interesting applications of POE's methodologies have been conducted at some hospices in the United States to identify relevant design/building factors and the surrounding green spaces in relation to users' needs to develop design support tools for optimal solutions (Movahed, 1995).

Another application was conducted in Canada (Anderson, 2008) to identify user-centered design 
criteria through the identification of quality factors terminal patients perceive as relevant. This suggested a new layout of the whole hospice and redesign of single patient rooms. In the pediatrics field, a study on applying POE's methodologies was carried out in the United States to assess the soothing effects of "therapeutic gardens" on patients, relatives, and staff and obtain information on spaces' use (Sherman et al., 2005). Relevant studies in the United Kingdom identified an effective method to proceed along with some design alternatives. One of the Maggie's Centers in Scotland was a case study of POE methodologies (Stevenson \& Humphris, 2008), which led to recommendations for the design of new Maggie's Centers and the development of further evaluation methodologies for other smaller healthcare buildings.

\section{Objective}

POE application is relevant for hospice specificity (Ferrante, 2008; Rowlands \& Noble, 2008). As regard to frail users, the perceptive factor can affect more relevantly rather than in other social and health facilities. Hospices are the places where patients and their relatives should find protection, privacy, safety, and comfort (Verderber \& Realfuenzo, 2006).

We conducted tests to comply with the minimum technological and structural requirements (provided for by the DPCM January 20, 2000). This was a guidance to hospices' design as a result of users' perception and use of spaces after redesign and implementation through POE application. The purpose is to explore further implementation of current standards into design strategy for new hospices or refurbishment of existing ones.

In particular, the objectives of this study are to:

apply POE methodologies to palliative care facilities and hospices,

evaluate the design and space suitability against the specific psychological needs of frail users, and

define indications for improving the design quality to support planning of new hospices or refurbishment of existing ones.
Consistently with the second objective, we pursued to:

a. evaluate the impact of each environmental factor on users' psychoemotional reactions,

b. identify factors that patients and their families perceive as relevant, and

c. identify suitable design procedures to improve the hospice design.

Through applying a relevant POE level, the research target is to detect whether and how patients and their families perceive certain design features that might affect privacy, acceptance, well-being, and security in certain functional areas and characteristic spaces (subplaces) of the hospice.

\section{Method}

Relatively to the objective "apply POE methodologies," the study involved a self-administered questionnaire to patients and family members in some Italian sampled hospices.

Given the heterogeneity of hospices in Italy, we conducted a preliminary study to find out some general common criteria and specific features. This study could allow an easier representative sampling of buildings to conduct the POE. The starting data for the preliminary study were provided by the second official survey on hospices prepared by the Ministry of Health in collaboration with the Italian Society of Palliative Care published in 2010. Also basing on Italian hospice legislation, which-since 2000requires the construction of new buildings for palliative care (hospice), we selected independent hospices. In Italy, there are many palliative care wards inside hospitals, but after extensive discussions with palliative care experts, we believe independent hospices are more effective and responsive to privacy of patients and family members.

We summarize the selection criteria of eight sampled hospices as follows:

National geographical area: Four, one, and three hospices, respectively, in North, central, and South/Islands Italy. 
Activation time: hospices running at least in the last 6 years.

Number of beds: at least 15 beds.

Accreditation of the facilities regarding national technical regulations: according to the DPCM 2000. Therefore, they have almost identical minimum requirements and were built or renovated with public funds.

Location context: urban contexts, also for specific aspects such as green areas, design, and space features of relevant functional areas directly affecting patients' well-being.

We selected specific spatial areas of observation from many research activities we have conducted on hospices from 1999 to presently.

The target was to identify essential design features and provide tools to support design, through qualitative and quantitative criteria and parameters related to specific therapeutic activities. These were with a holistic approach and focused on physical, psychological, and social factors of patients and their families. (Niedzielski et al., 2016). These factors led to the selection of the spatial areas of observation and related fundamental requirements to be evaluated.

The perceived hospital environment quality indicators (PHEQIs) is a reference tool validated by studies and research (Andrade et al., 2012; Fornara, 2005; Fornara et al., 2006) for measuring users' perception of quality and humanization of care environments.

\section{The perceived hospital environment quality indicators (PHEQIs).}

Although hospices differ considerably from hospitals in terms of intensity of care and organizational/functional/technological complexity, they share the same need for humanized spaces. Through the PHEQI test for measuring the perceived humanization in care environments, we can identify an outline of physical-spatial and social-functional factors of humanization.

So, to better adapt the PHEQIs measurement tools to hospices, we carried out an implementation activity of the humanization indicators (Figure 1) and considered the peculiar characteristics of a hospice in terms of users, daily care practices, and design quality that differentiate it from other care facilities.

These features can be found in the different "behavioral settings" (Barker, 1987) and therefore in the subplaces chosen, including outdoor areas (defined as building access, parking, and green areas), common indoor areas (defined as areas for social activities of for patients' family members), and patients' rooms (can also accommodate close relatives). For these places, we developed a reliable set of items for each specific perceived quality factor to measure, including appearance/sense of welcome, accessibility/use, orientation, environmental, visual, acoustic, olfactory, tactile, and privacy/control of the surroundings. The expertise of professionals in environmental psychology and designers cooperated with the study.

\section{Evaluation Tools and Participants Involvement}

The application context included a sample of eight independent hospices (which appear in this article anonymized and identified only with a number) in different geographical areas of Italy. It involved at the same time a self-administered questionnaire among 135 people, including 51 patients and 84 relatives/caregivers, of which 74 were women and 61 men, aged between 21 and 95 years, with an average age $(A)$ of 55.6 and a standard deviation $(S D)$ of 14.7. As to education, $11.1 \%$ of them have primary school diploma, $22.2 \%$ middle school, $32.6 \%$ secondary high school, and $25.2 \%$ university degree.

We prepared a self-filled questionnaire with adapted items included in PHEQIs and new items to detect specific characteristics of hospices.

We structured the questionnaire in three distinct sections with items related to the physicalspatial factors of three different subplaces of the hospices as follows: (1) outdoor areas (42 items), (2) common indoor areas (64 items), and (3) patients' rooms (66 items). Occupants answered on a 5-point Likert-type scale for each item from 0 (total disagreement) to 4 (total agreement). A fourth section of the questionnaire included three items on total satisfaction with the hospice and social-demographic indicators. Doctors and 


\begin{tabular}{|c|c|c|c|c|c|c|c|c|}
\hline \multicolumn{9}{|c|}{$\begin{array}{l}\text { Now focus your attention on PATIENT'S ROOM } \\
\text { Please indicate your degree of agreement or disagreement with the statements below } \\
\text { (referring to the patient's room and accompanying person/family member), using the } \\
\text { following scale: }\end{array}$} \\
\hline & & & \multirow{2}{*}{$\begin{array}{c}\begin{array}{c}\text { Completely } \\
\text { Disagree }\end{array} \\
\mathbf{0} \\
\end{array}$} & \multirow{2}{*}{$\begin{array}{c}\text { Quite at odds } \\
\mathbf{1} \\
\end{array}$} & \multirow{2}{*}{\begin{tabular}{|c|}
$\begin{array}{c}\text { Neither Disagree } \\
\text { Nor Agree }\end{array}$ \\
$\mathbf{2}$ \\
\end{tabular}} & Quite Agree & \multicolumn{2}{|l|}{ Totally agree } \\
\hline & & & & & & 3 & 4 & \\
\hline 1 & \multicolumn{2}{|c|}{ The fuminure in this room is in good condition } & 01234 & 26 The room is thallow & ram the view from the patient's bed & 01234 & 4s Inside the room there are perfiume diffuers & 01234 \\
\hline 2 & \multicolumn{2}{|c|}{$\begin{array}{l}\text { The walls, floors and ceilings in this room are in poor } \\
\text { coodition. }\end{array}$} & 01234 & $27 \begin{array}{c}\text { The coluars of the } \\
\text { bripht }\end{array}$ & Is and hoors from the romam are toos & $0 \longdiv { 0 1 2 3 4 }$ & 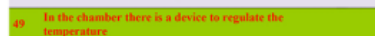 & $012 \overline{0}$ \\
\hline 3 & \multicolumn{2}{|c|}{ The furmishing in this room are unpleasant } & 01234 & 28 The colours of the fif & nature and oramaments in the room & $0, \overline{1234}$ & \multirow{2}{*}{ 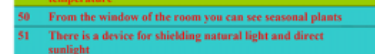 } & 01234 \\
\hline 4 & \multicolumn{3}{|c|}{ The walls, flooss and exilings in this room are well maintained 01234} & \multicolumn{2}{|c|}{ 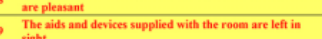 } & $\overline{01234}$ & & 01234 \\
\hline 5 & \multicolumn{2}{|c|}{ The furniture in this romm is in poor condition. } & 01234 & & $\longdiv { 0 1 2 3 4 }$ & 32 Arrificiall light can be regulateded in the room & 01234 \\
\hline 6 & \multicolumn{2}{|c|}{ The walls, floos and eelings in this room have nice colours. } & 01234 & \multicolumn{2}{|c|}{ 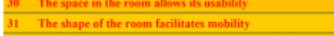 } & 01234 & 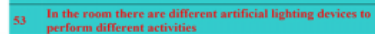 & 0.1234 \\
\hline 7 & \multicolumn{2}{|c|}{ The walls, floos and eclings in this room loek unpleasant. } & 01234 & \multicolumn{2}{|c|}{ 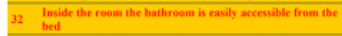 } & 0.01234 & 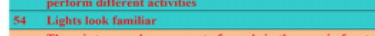 & 01234 \\
\hline 8 & \multicolumn{2}{|l|}{ This wakingy patient ara is chan. } & 01234 & \multicolumn{2}{|c|}{ 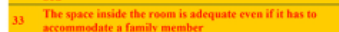 } & 01234 & $\begin{array}{l}55 \text { There i t toom much movecenent of people in the area in froat } \\
\text { of the room }\end{array}$ & 01234 \\
\hline & \multicolumn{2}{|c|}{ 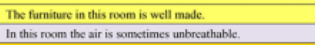 } & 01234 & \multicolumn{2}{|c|}{34 The space around the hed allows for simple and eary } & $0 \quad 01234$ & 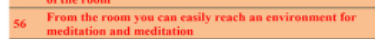 & $0 \longdiv { 1 2 3 4 }$ \\
\hline$\frac{11}{11}$ & \multicolumn{2}{|c|}{ 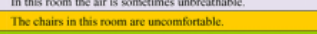 } & 01234 & & 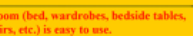 & $\sqrt{01234}$ & 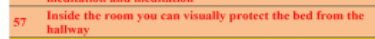 & $0 \longdiv { 1 2 3 4 }$ \\
\hline 12 & 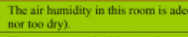 & uate (neithe tros humid & 01234 & 36 The bed iseasily yd & table & 0123.4 & $\begin{array}{l}\text { S8 In the roman there are elcectronic devices which are } \\
\text { cantrolled from the bed }\end{array}$ & $0 \longdiv { 1 2 3 4 }$ \\
\hline 13 & 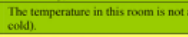 & 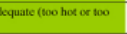 & 01234 & 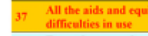 & ment in the roem do not preseat any & 0.1234 & 59 In the room there are no elements that hinder walking & 0.1234 \\
\hline 14 & The windous sin this nom are now $\mathrm{w}$ & yclaan. & 01234 & 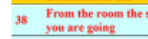 & ragge makes it easy to gect to where & $012 \quad 14$ & 6e Room door can be openend effortilestly & 0.1234 \\
\hline & More windows are nededed in this ror & & $\frac{01234}{01234}$ & 39 From the room it & Micichl to find your way around & 01224 & $\begin{array}{l}\text { In the room the furniture and equipment can be moved } \\
\text { efforlessty }\end{array}$ & 0.1234 \\
\hline$\frac{16}{17}$ & $\begin{array}{l}\text { This room is pootyly lit thy sunlighth } \\
\text { This row has lare windown }\end{array}$ & & $\frac{01234}{01234}$ & 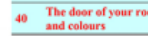 & ni is easily identifiable with symbooks & $012: 4$ & 62 The room has an enclosed space to store valuables & 0.1234 \\
\hline 18 & Thare is sufficicint air exchange fure & outside in this rom. & 01234 & 41 Nella camera c'e que & & 0.1214 & $\begin{array}{l}\text { 63. It is possible to personalize the room with furniture and/or } \\
\text { personal objects }\end{array}$ & 0.1234 \\
\hline 19 & Girech arcas can be sen from the w. & dows in this room. & 0.1234 & 42 There is linte naitec & the rom & $0.12: 4$ & 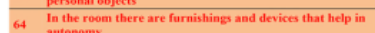 & $0 \longdiv { 1 2 3 4 }$ \\
\hline 20 & In this romm the intensity of artificin & light is stistatatcoy. & 01234 & 43 In the romen you can & Ear noibe coming from the corridons & 01224 & of antonomy & 07234 \\
\hline & This rom is large enouphe & & 01234 & 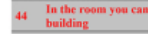 & ear nabiec coming from outside che & 01214 & 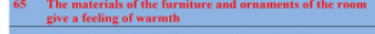 & 01234 \\
\hline & $\begin{array}{l}\text { The room look familiar } \\
\text { The room is comy }\end{array}$ & & $\frac{01234}{01234}$ & 45 Inide the chamber & ere are noiece deriving from systems & .01294 & 66 The surfines of the furniture are pleasaat to the tooch & 0,1234 \\
\hline$\frac{23}{24}$ & $\begin{array}{l}\text { The room is casy } \\
\text { The room is spacious }\end{array}$ & & 01234 & 46 In the room the sule & of disinfectant (or medikines) is too & $0 1 2 \longdiv { 4 3 4 }$ & & \\
\hline & 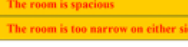 & eof the patient's bed & 01234 & 47 Iniside the chamber & e air exchangec can be adjusted & $0 \longdiv { 0 1 2 3 4 }$ & & \\
\hline & & & Groul & ping of items by & physical-spatial qual & alities/requi & irements & \\
\hline & & Physical- & -Spatial Aspe & ects: PATIENT'S I & оOM & & & \\
\hline & & Requirements : & & Appearance/sense & f welcome & & n. Item: $8-14-22-23$ & \\
\hline & & Requirements : & & Accessability/usab & & n. Item: $11-2$ & $\begin{array}{r}21-24-25-30-31-32-33 \\
-34-58-59-60 \\
\end{array}$ & \\
\hline & & Requirements : & & Orientation & & & n. Item: $38-39-40$ & \\
\hline & & Requirements : & & Acoustic well-bein & & & n. Item: $41-42-43-44-45$ & \\
\hline & & Requirements & & Olfactory well.bei & & & n. Item: $10-46-48$ & \\
\hline & & Requirements : & & Environmental we & -being & & n. Item: $12-13-18-47-49$ & \\
\hline & & Requirements & & Visual well-being & natural light & n. Item: & $15-16-17-19-26-50-51$ & \\
\hline & & & & Visual well being & artificial light & & n. Item: $20-52-56-54$ & \\
\hline & & Requirements r & & Privacy/control of & he surroundings & & Item: $55-56-57-62-63-64$ & \\
\hline & & Physical-Sp & patial Aspects & s: FURNITURES, & patient's rooms and su & urroundings & & \\
\hline & & Requirements r & & Appearance/sense & f welcome & n. Item: 1 - 3 & $-5-9-28-29$ & \\
\hline & & Requirements $\mathrm{r}$ & & Accessibility / usa & & n. Item: $35-3$ & $36-37-61$ & \\
\hline & & Requirements r & & Tactile well-being & & n. Item: $65-66$ & & \\
\hline & & Physical-Sp & patial Aspects & s: WALLS, FLOC & RS AND CEILINGS & & & \\
\hline & & Requirements $\mathrm{r}$ & & Appearance/sense & f welcome & & n. Item: $2-4-6-7-27$ & \\
\hline
\end{tabular}

Figure I. By way of example, the figure shows a summary of the questionnaire and in particular the part relating to the physical-spatial aspects of the private area (patient's room). The different colors identify the items relating to each individual requirement evaluated. The red items represent the adaptation of the perceived hospital environment quality indicators to the specific hospice area.

nurses carried out recruitment of participants, administration, collection, and delivery of the questionnaires. Patients were selected for their health conditions and their relatives were also involved. All privacy procedures were respected. We collected data between May and June 2013. 


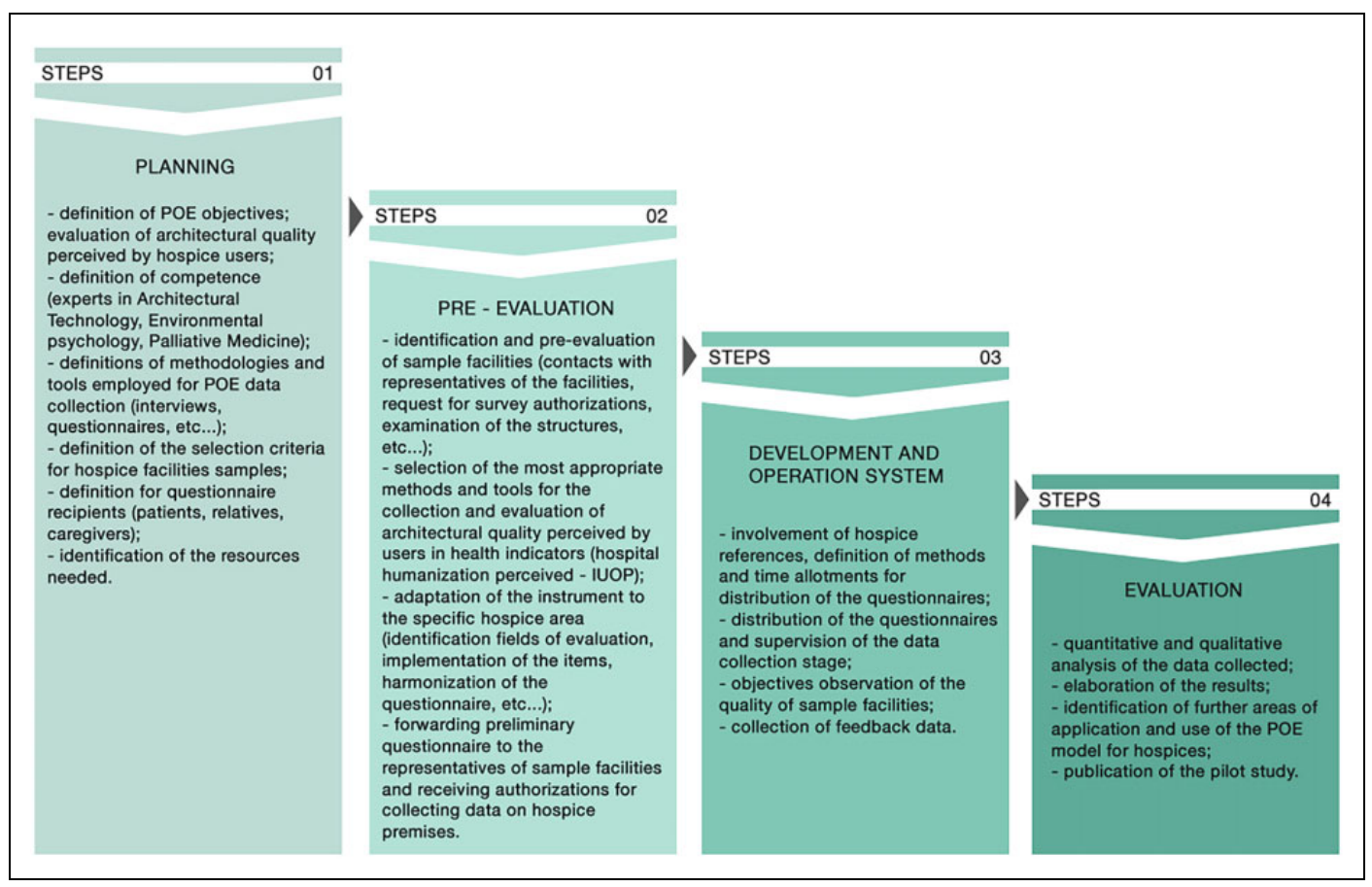

Figure 2. The four steps characterizing the application of the post-occupancy evaluation method to the pilot study on hospices. The process has been (re)measured on these specific facilities that have specific features completely different from those found in "healthcare buildings." The steps indicated provide an organic picture of the procedures.

The research process can be summarized in four phases: (1) planning, (2) prevalence, (3) development and conduction, and (4) evaluation (Figure 2).

1. The planning phase included definition of POE objectives, that is, the evaluation of design quality factors in terms of privacy and acceptance through users' perception; the expertise, for example, technologists, environmental psychologists, and others for the evaluation of design choices through users' satisfaction; the level of in-depth analysis of the first POE level; tools for data collection, that is, anonymous questionnaires and interviews; the object of the evaluation-a sample of eight hospices; the selection criteria of the sample (year of establishment, compliance with accreditation for palliative activities, geographical distribution, accommodation capacity, location, construction time, and management type); the subjects involved in the evaluation (patients and relatives/guardians); and the resources (personnel, costs, and equipment).

2. The prevalence phase enabled the identification and prevalence of the sampled hospices (hospices' contact persons, request of authorizations for the survey, examination of the hospices, etc.), the selection of the most appropriate methods and tools for the detection and evaluation of the design quality perceived by the users (PHEQIs indicators), the tool adaptation to the specific hospice area (identification of assessment areas, implementation of the items, harmonization of criteria and parameters, etc.), and the preliminary questionnaire reading by the contact person of the sampled hospices for the survey authorizations release and compliance to ethics guidelines.

3. The third phase of development and conduction involved contact persons for the 
definition of methods and timescales for the questionnaire administration, questionnaire administration and monitoring of the data collection, and the observation of the qualities of the sampled hospices by expert architects to compare the results. The results of this observation are shown in Table 1.

4. The fourth phase of evaluation included a quantitative and qualitative analysis of the collected data, the processing of the results and the acquisition of the relative results, a first method of use for the planning and design phases of the emerging results, and the identification of further areas of indepth research.

\section{Results}

A first result was the identification of reliable indicators. The analysis of the main factors carried out for each set of items (relating to specific indicators expected in the three areas of the hospice) and the subsequent indoor reliability checks (using Cronbach's $\alpha$ index) provided three indicators of perceived quality for outdoor areas, six indicators of perceived quality for common indoor areas, and four indicators of perceived quality for patients' rooms. The indicators of indoor reliability are globally acceptable (Cronbach's $\alpha$ between .90 and .64) since only three of the 11 indicators fall below the .70 threshold (Table 2).

\section{Perceived Quality Indicators for Outdoor Areas}

For outdoor areas, the three indicators include appearance of outdoor areas, green areas, and usability. Appearance of outdoor areas and maintenance of the hospice from outside relevantly affect users' perception. The presence/ absence of green areas and their usability is relevant for outdoor activities (Cooper \& Barnes, 1999). We consider usability as possibility to easily reach the entrance of the building. It also includes items inclusive of car parks, orientation systems, and recognition of the key access.

\section{Perceived Quality Indicators for Common Indoor Areas}

For common indoor areas, the six indicators are orientation, acoustic comfort, environmental and olfactory comfort, appearance and care, usability of the spaces, and views of the outside and natural lighting. Orientation includes spaces recognizability and spatial clues and signage systems that design should make available. Acoustic comfort includes presence/absence of noise outside and inside. Environmental and olfactory comfort includes temperature, air changes, and presence/ absence of unpleasant odors. Appearance and care include materials and state of preservation of different space features (floors, coverings, ceilings, and false ceilings, etc.). Usability is for ease of use of spaces, paths, connective systems, and doors. Views of the outside and natural lighting include presence/absence of pleasant views of green areas and the quantity/quality of light based on the number of windows, glass surface, and cleanliness.

\section{Perceived Quality Indicators for Patients' Rooms}

For the patients' rooms, the four indicators include appearance and maintenance, usability, acoustic comfort, and artificial lighting. Appearance and maintenance affects feeling of welcome and pleasantness and care of private space features (floors, walls, false ceilings, etc.) and furnishings.

Usability relates to room size, maneuvering space, space for family members, and accessibility. Acoustic comfort includes presence/absence of noise from common indoor and outdoor areas.

Artificial lighting includes presence/absence of lighting devices with customized lighting levels for patients and family members.

After reliable indicators were identified, a second result was to calculate the average score by aggregating the scores received from items from each indicator.

\section{Criticality of Some Indicators for the Different Subplaces}

Generally, the results report a substantially positive response about the overall satisfaction indicator, 
Table I. Synoptic Outline of the Evaluations Acquired for the Eight Hospice Structures Assumed as Sample.

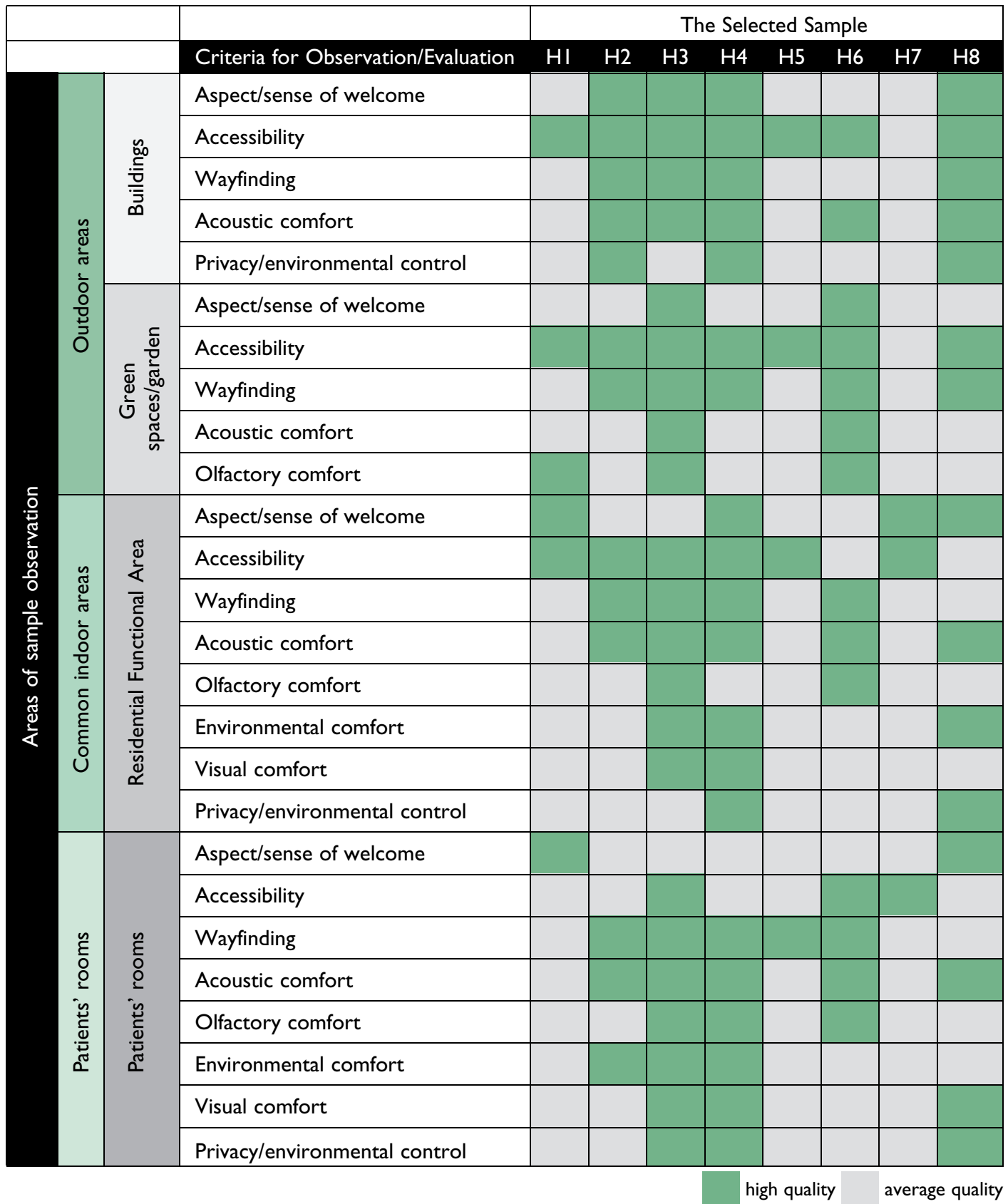

Note. The selection of the standards to use and the identification of the evaluation ranges to examine have been made through a strict interdisciplinary confrontation inside the working group: The data collection has taken place in collaboration with the staff in service in every single structure so that, apart from increasing the spectrum of the disciplinary contributions, a correct interpretation of the answers of users that can be considered as "weak" as for many points of view has been assured. The results emerged, although partial because the research is still in progress, already allow the identification of new inputs for the design stage that assure to the users a more suitable fruition of the spaces. 
Table 2. Indicators of perceived environmental quality in the Hospices: number of items and indicators' internal consistency coefficients $(\mathrm{N}=135)$.

\begin{tabular}{llrr}
\hline Subplace & Indicators & $N$ Item & Cronbach's $\alpha$ \\
\hline Outdoor areas & Accessibility & 6 & .84 \\
& Green areas & 6 & .84 \\
& Aesthetical pleasantness and Upkeep & 7 & .80 \\
\hline Common indoor areas & Noiselessness & 6 & .80 \\
& Wayfinding & 10 & .78 \\
& Views and natural lighting & 8 & .65 \\
& Aesthetical pleasantness and upkeep & 14 & .85 \\
& Climate and odors & 7 & .64 \\
& Space usability & 6 & .73 \\
\hline Patients' rooms & Spatial comfort & 14 & .90 \\
& Aesthetical pleasantness and upkeep & 11 & .82 \\
& Noiselessness & 5 & .76 \\
& Artificial lighting & 3 & .66 \\
\hline
\end{tabular}

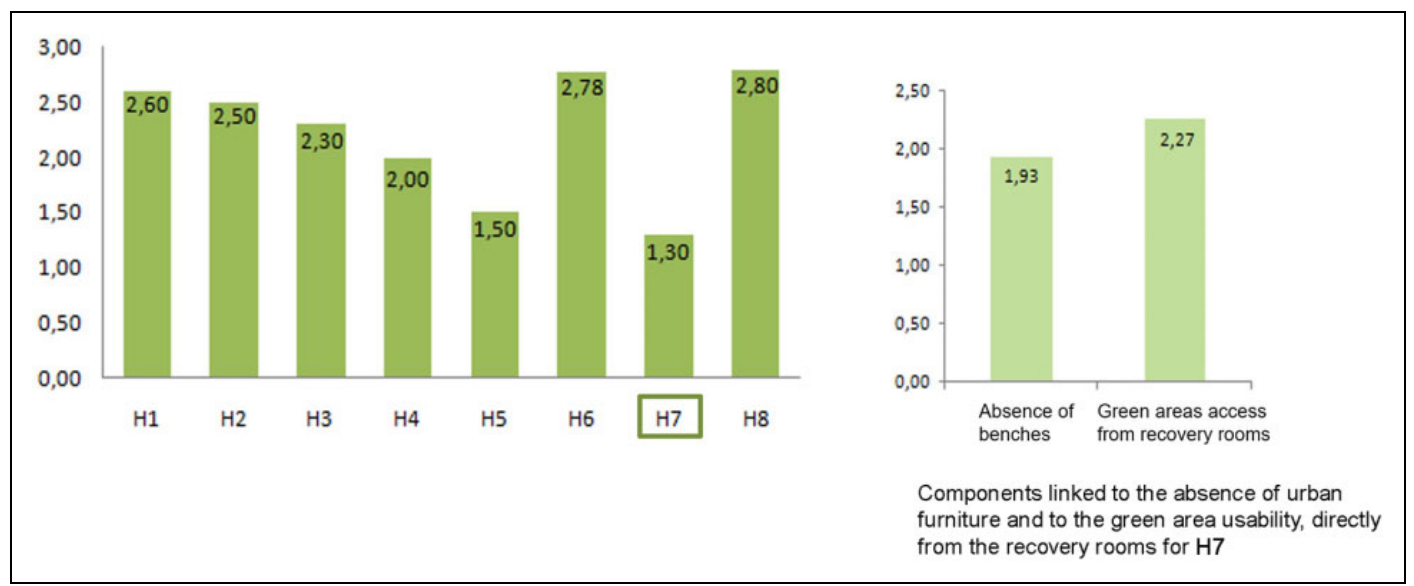

Figure 3. Outdoor areas: Green areas indicator.

which was detected through the fourth section of the questionnaire. This shows a good physical-spatial quality of the hospices with the perceived quality of each subplace.

Users expressed a favorable and satisfactory perception of a particularly efficient organizational methods, fully suitable assistance levels, and an overall positive psychological feeling that affected the evaluation of design aspects. The favorable responses from the questionnaires show a prevalence of the quality of the patients' rooms in terms of hospitality, familiar feeling, good spaces availability, and furniture quality. Other items in the questionnaire with a higher average satisfactory rate are the quality of green areas users perceive outside and from the bedroom windows. However, from the analysis of the relations between the global satisfaction indicator and the specific indicators identified for each subplace, some emerging critical points seem to require further suggestions.

For outdoor and green areas, the accessibility/ usability indicator sometimes detected missing green areas that directly serve the rooms and a poor equipment and urban furniture for socializing activities (Figure 3 ). 


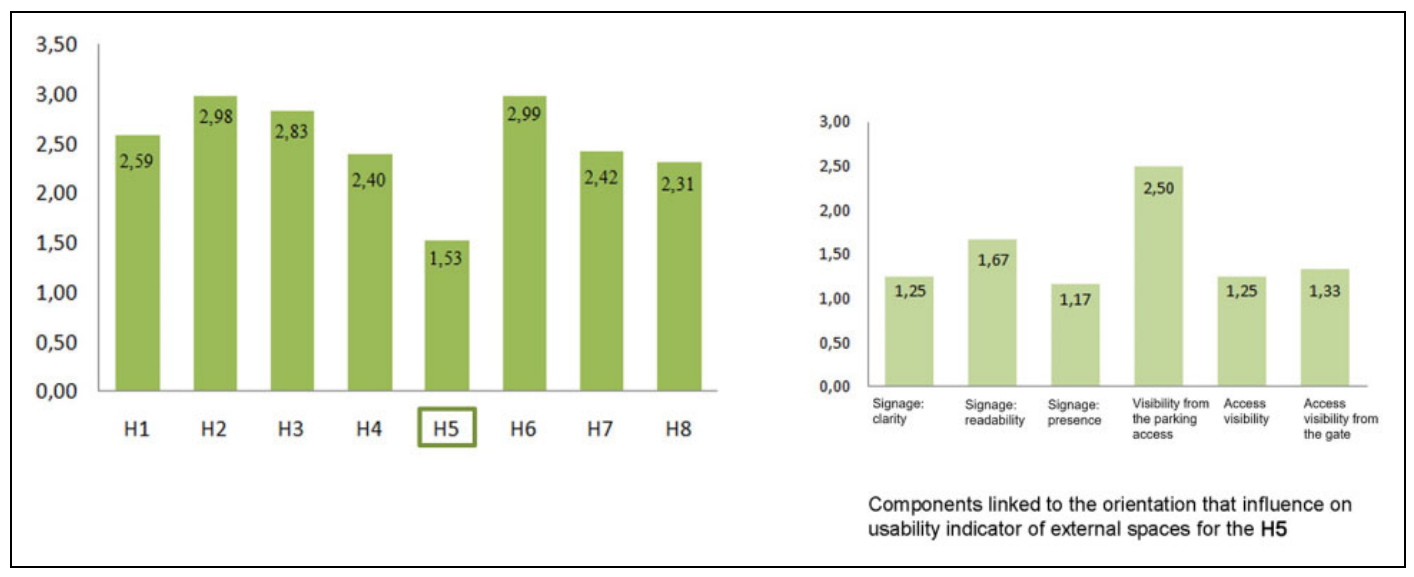

Figure 4. Outdoor areas: Accessibility/usability indicator.

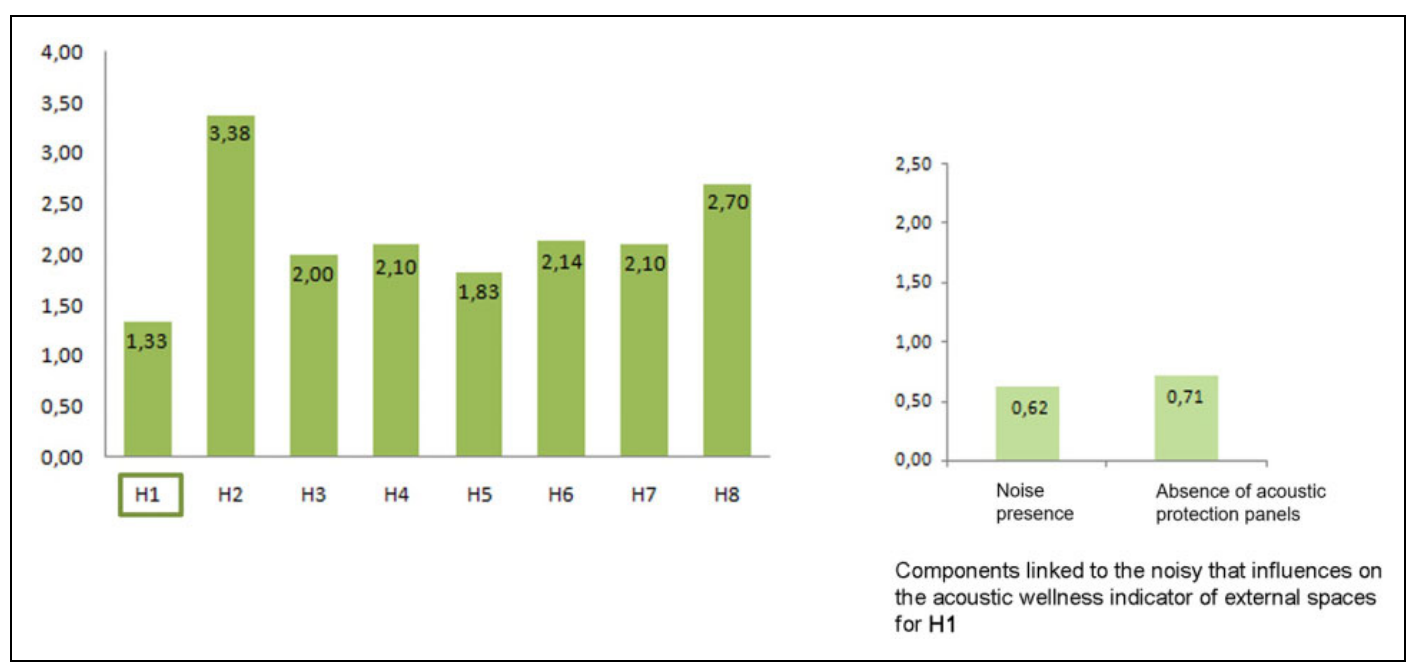

Figure 5. Outdoor areas: Acoustic well-being indicator.

Some responses below the average were also found for the difficulty of use of outdoor areas due to missing orientation signage and the hard recognizability of the main entrance to the building (Figure 4).

The acoustic comfort indicator has sometimes detected among family members a noise level in outdoor areas during relaxation and often poor acoustics barriers to shield such spaces from the streets (Figure 5).

As regard the common indoor areas, the satisfaction is very high. Emerging criticalities include the usability indicator of connecting areas and corridors: They were perceived too long or, sometimes, not usable because of obstacles (Figure 6).

Also, the indicator of the quality of views of the outside and natural lighting detects few windows for outside views in connecting areas. In some cases, there are no window shutters against direct exposure to sunlight.

For the subplace of patients' rooms, satisfactory rates are very high. However, critical points have been frequently found for the artificial lighting indicator and the visual well-being. Patients sometimes complained about the lacking 


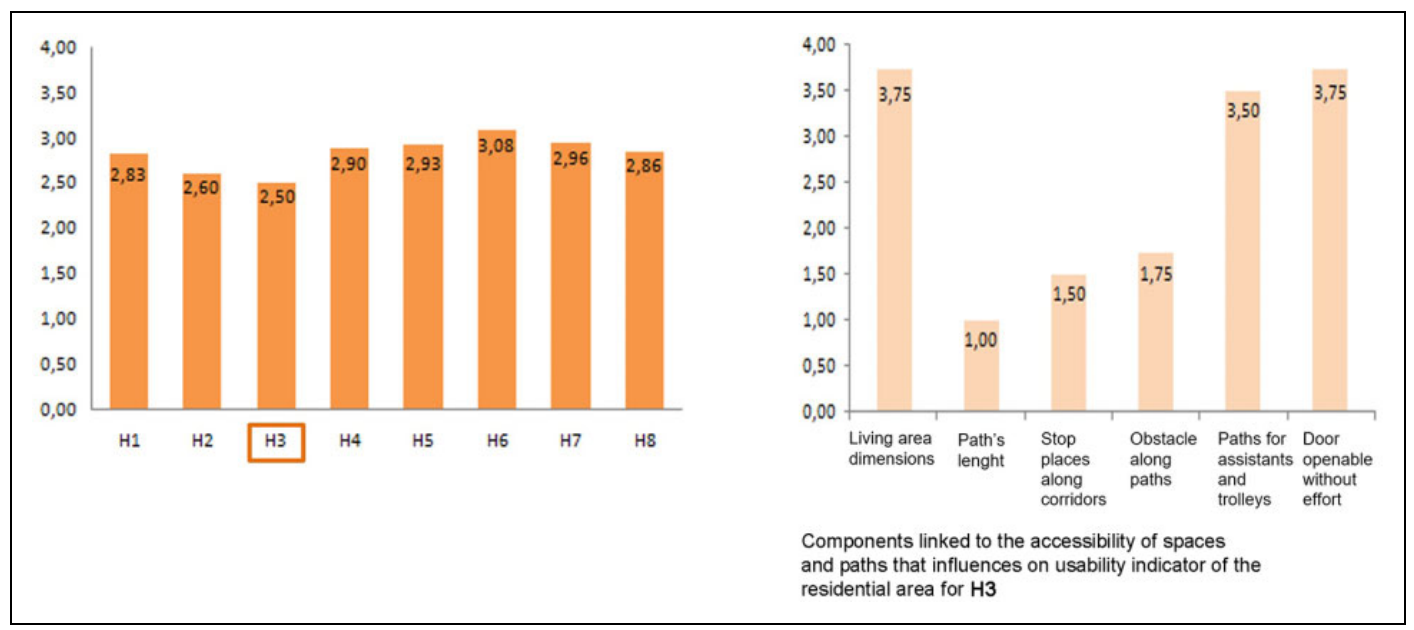

Figure 6. Common indoor areas: Usability indicator.

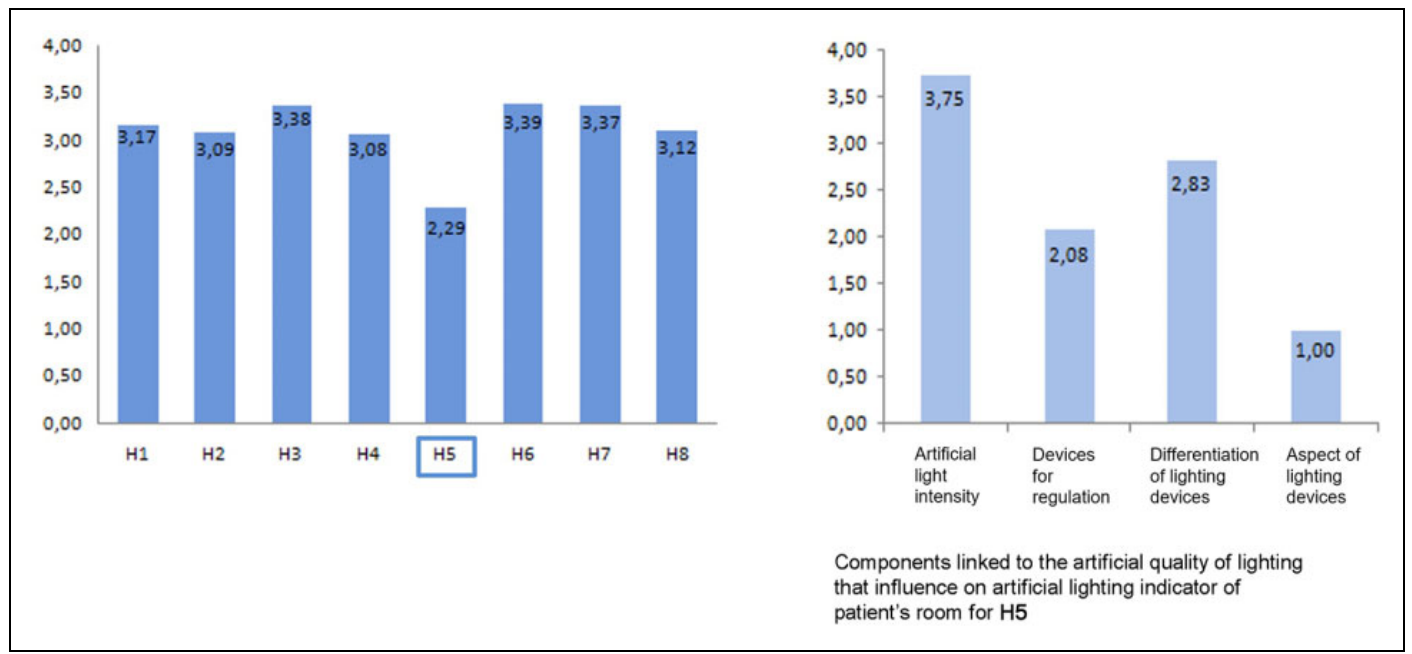

Figure7. Patients' rooms: Artificial lighting indicator.

customization of the lighting system (spread and spotlight) and intensity. However, the overall illuminance level appears satisfactory (Figure 7).

The acoustic comfort indicator also scores lower because of noises from corridors and sometimes from lifts and air conditioning system.

\section{Discussion of Results and Design Suggestions}

In relation to the criticalities, we considered some design assumptions to improve the critical physical/spatial factors coming from the questionnaires. Relevance of accessibility/usability of outdoor spaces is evident from data analysis. Improvements could involve redesign of wayfinding systems, access recognizability through orientation signage, and paths/flooring with color contrasting materials. Improvements are also required for furniture and equipment in green areas.

For a better performance and comfort of acoustic comfort, it is advisable to shelter with green acoustic barriers that limit the road noise 
and could positively affect a sense of protection and amenity in outdoor areas. Finally, green areas and their care has proved one of the most relevant indicators on the overall quality of hospices. Thus, a major design suggestion is to the quality of existing outdoor areas and, for new construction, to include such design indicators within the building programs.

For common indoor areas, indicators are relevant for usability of connecting areas: We detected a poor usability due to obstacles along the path and lacking space. Some family members often misused common areas and for this they had a feeling of discomfort. A design suggestion for this issue is a reorganization of the layouts of hospices that provide proper socializing areas in close relation to the patients and a control of the sense of fatigue due to a too long distance.

Connecting areas are noisy. For the acoustic comfort indicator, design criteria include a better acoustic performance of the connecting horizontal and vertical partitions and of internal finishes (floors, walls, and false ceilings). In common areas, the indicator of visual comfort and natural light is also relevant to users' perception and scores considerably in the overall well-being of hospices. With few window surfaces, we recommend use of systems for natural light capturing, with a positive impact also on energy saving.

For patients' rooms, all the critical indicators detected users' need of customization of artificial light intensity and environmental requirements. Suggestions include use of different lighting fixtures for different activities (reading, resting, etc.) and different light intensity and control devices. We should apply the customization for adjusting heating indoor microclimate.

These first design indications are the base on which designers must work to improve the criticalities reported, together with all user-centered factors.

\section{Limits and Future Development}

The prospective scenarios from this study point out some limits and further insights. Although the study has paid great attention to the selection of a relevant sample of hospices, to contain time and costs and to collect information with greater accuracy, only a sample of eight hospices was selected. However, such hospices do not fully represent reality, but they rather appear inhomogeneous.

In fact, even though eight independent hospices were selected, five of them are from retrofit of existing buildings. Therefore, some design solutions were affected by the constraints imposed by existing buildings, thus making the indicators particularly critical about location, green areas, and noise.

In addition, enquired users do not include hospice staff, who may later be involved to add their suggestions to those of patients and family members. Patients' and families' preferences for areas and rooms also depend on their health status. We have paid a special attention to the interrelation between perceived design quality and stages of illness. Finally, we would consider extending evaluation to all the hospice functional areas and to the single rooms using the same set of indicators for the assessment and therapy area, the day hospice and waiting areas, for the general support services area, the hall with reception, common living rooms, and so on. By including all areas in the evaluation of a hospice, we can draft new planning guidelines to adapt hospice facilities already built under Law no. 39/1999 and to develop new hospices.

\section{Conclusions}

The management of POE in this specific sector enhanced merge between "design" and "applied research," by using interdisciplinary skills and "on-field" checking of how space quality can affect users. POE promoted transferability of research also by linking various disciplines through a constant interaction in every phase of the work.

The methodological validation process of a set of design quality indicators for care environments (PHEQIs) was a scenario for the specific field of observation. This led to definition of the best user preferences on physical-spatial factors in terms of design quality. Also, it led to the identification of the most critical indicators we need to consider during the design phase. Thus, we detected users' 
appreciation of the sampled hospices. We can also reaffirm how POE procedures are an essential tool both for the client (planning phase) and for the technicians (design phase). In fact, the first results of this study helped building reprogramming and layouts revising with appropriate technical solutions. It also provides enough references to update current regulations in Italy (see documents produced for the Ministry of Health for the State-Regions Conferences, under Law 38/2010).

\section{The methodological validation process of a set of design quality indicators for care environments (PHEQIs) was a scenario for the specific field of observation. This led to definition of the best user preferences on physical-spatial factors in terms of design quality. Also, it led to the identification of the most critical indicators we need to consider during the design phase.}

Specifically, the research results helped to define a performance framework in direct relation to the specific needs of "frail occupants," thus reinforcing the need and relevance on the evidence-based design principles (Joseph et al., 2014; Stichler, 2015). A relevant consideration from users' groups in the conducted POE is their average age based on different age groups. This highlighted how the space quality is a key in incurability situations.

The results we obtained are both methodological and operational. We have defined a close link between "design" and "applied research," suggesting suitable implementations within the design guidance tools that can be replicable in different international contexts with hospices for the terminally ill.

From this study, we can also take out a generalizable knowledge of the hospice functioning. This can be compared to other European countries. Moreover, we recognize a design relevance that involves all the actors of the building process to optimize the design quality of the spaces as a key address.

Finally, through a sensible and on-field POEs, we can foresee in advance the perception level of users and stakeholders in terms of space quality. Thus, in the design phase, we need to use the results of the POEs to identify factors that patients and their families perceive as relevant in design and spatial quality and to include them from the early stages of designing new hospices or retrofitting existing ones.

\section{Practical Implications}

- Monitoring to what extent and how a hospice facility fulfills its intended functions over time, and therefore evaluating the extent to which the economic investment was optimized (efficiency).

- Correlation between quality of spaces and of provided services in hospice facilities (efficacy).

- Proper consideration, in planning and design phases, of indications deriving from the results of ex post evaluation, so that to ensure additional quality levels.

- Encouragement to apply POEs, currently rarely implemented, which, once consolidated, could substantially change the planning and design processes itself.

- Translating the obtained results into design suggestions through summary information, to guide designers in their technological, functional, and morphological choices.

- Outlining design solutions in response to the critical issues highlighted by the results of the POE.

- Using such results to recalibrate hospice building programs, revisiting the layouts, implementing current regulations, developing design guidelines in order to adapt the existing hospice structures as well as to create new ones, and following the criteria based on the evidence obtained from the research.

\section{Declaration of Conflicting Interests}

The author(s) declared no potential conflicts of interest with respect to the research, authorship, and/or publication of this article. 


\section{Funding}

The author(s) received no financial support for the research, authorship, and/or publication of this article.

\section{ORCID iD}

Teresa Villani (D) https://orcid.org/0000-00033665-1609

\section{References}

Alvaro, C., \& Atkinson, C. (2013, July). Healthcare facility design, psychosocial well-being and health: A scientific approach to assess impact. World Health Design, 6(3), 60-67.

Anderson, D. (2008, April). Palliative care unit design: Patient and family preferences (pp. 62-67). World Health Design.

Andrade, C., Lima, L., Fornara, F., \& Bonaiuto, M. (2012). User's views of hospital environmental quality: Validation of the perceived hospital environment quality indicators (PHEQIs). Journal of Environmental Psychology, 32(2), 97-111.

Barker, R. G. (1987). Prospecting environmental psychology: Oskaloosa revisited. In D. Stokols \& I. Altman (Eds.), Handbook of environmental psychology (Vol. 2., pp. 1413-1432). Wiley.

Cooper Marcus, C., \& Barnes, M. (1999). Healing gardens. Therapeutic benefits band design recommendations. John Wiley \& Sons.

Ferrante, T. (2008). Hospice: Luoghi, spazi, architettura. Alinea.

Ferrante, T. (2013). Evaluation of perceived quality: Hospice: A pilot study. Franco Angeli.

Fisk, W. J. (2002). How IEQ affects health, productivity. ASHRAE Journal-American Society of Heating Refrigerating and Airconditioning Engineers, 44(5), 56-60.

Fornara, F. (2005). Users' evaluative responses to spatio-physical humanization: The case of hospital environments. In B. Martens \& A. G. Keul (Eds.), Designing social innovation: Planning, building, evaluating (pp. 231-240). Hogrefe \& Huber.

Fornara, F., Bonaiuto, M., \& Bonnes, M. (2006). Perceived hospital environment quality indicators: A study of orthopaedic units. Journal of Environmental Psychology, 26(4), 321-334.

Harvey, J. (1984). Post occupancy evaluation: Do you meet users' needs? Dimensions in Health Service, 61(6), 12-13.
Joseph, A., Quan, X., Keller, A. B., Taylor, E., Nanda, U., \& Hua, Y. (2014). Building a knowledge base for evidence-based healthcare facility design through a post-occupancy evaluation toolkit. Intelligent Buildings International, 6(3), 155-169.

Kader, S. (2016). Development of hospice environmental assessment protocol (HEAP): A post occupancy evaluation tool [Doctoral dissertation, University of Kansas]. http://hdl.handle.net/1808/21798

Kader, S. (2017). Environmental characteristics that enable dying patients to exercise choice and personal preference (Proceedings). Proceedings of the EDRA48 conference on voices of place (pp. 116-126). https://cdn.ymaws.com/www.edra.org/ resource/collection/8F43AFA7-151E-4AE2-8E3 FF71DF0ABF411/EDRA-Proceedings-2017.pdf

Millet, A., Abi Akle, A., \& Legardeur, J. (2018, July 5-6). Human centred criteria for healthcare design. In 25ème colloque des Sciences de la conception et de l'innovation (CONFERE 2018). Budapest, Hungary. CCSD.

Movahed, A. (1995). Physical and environmental features that contribute to satisfaction with hospice facilities [Dissertation and Theses, Paper 1283, Portland State University].

Niedzielski, O. K., Rodin, G., Emmerson, D., Rutgers, J., \& Sellen, K. M. (2016). Exploring sensory experiences and personalization in an inpatient residential hospice setting. The American Journal of Hospice and Palliative Care, 33(7), 684-690.

Preiser, W. F. E. (1995). Post-occupancy evaluation: How to make buildings work better. Facilities, 13(11), 19-28.

Preiser, W. F. E., Rabinowitz, H. Z., \& White, E. T. (1988). Post-occupancy evaluation. Van Nostrand Reinhold.

Rigby, J. (2008). Improving the environment for hospice in-patients. Lancaster University CECo Scholarship Holder, East Cheshire Hospice, Macclesfield, Cheshire.

Rigby, J., Payne, S., \& Froggatt, K. (2010). Review: What evidence is there about the specific environmental needs of older people who are near the end of life and are cared for in hospices or similar institutions? A literature review. Palliative Medicine, 24(3), 268-285.

Rowlands, J., \& Noble, S. (2008). How does the environment impact on the quality of life of advanced cancer patients? A qualitative study with implications for ward design. Palliative Medicine, 22(6), 768-774. 
Sagha Zadeh, R., \& Eshelman, P. (2019, January). Palliative design meets palliative medicine: A strategic and judicious approach to the design, construction, and operation of healthcare facilities to improve quality of life and minimize suffering for patients, their families, and their caregivers. Health Environments Research \& Design Journal, 12(3), 179-186.

Sherman, S. A., Varni, J. W., Ulrich Roger, S., \& Malcarne, V. L. (2005). Post-occupancy evaluation of healing gardens in a pediatric cancer. Landscapeand Urban Planning, 73(2-3), 167-183.

Stevenson, F., \& Humphris, M. (2008). Post occupancy evaluation of the Dundee Maggie Centre, ecological design group. School of Architecture University of Dundee, Bute Medical School, University of St. Andrews and the Maggie's Centres.

Stichler, J. F. (2015). Evaluating evidence-based studies and design projects. Health Environments Research \& Design Journal, 8(3), 96-104.
Ulrich, R., Berry, L., Quan, X., \& Parish, J. T. (2010). A conceptual framework for the domain of evidence-based design. Health Environments Research \& Design Journal, 4(1), 95-114.

Ulrich, R., Zimring, C., Zhu, X., DuBose, J., Seo, H. B., Choi, Y. S., \& Joseph, A. (2008). A review of the research literature on evidence-based healthcare design. Health Environments Research \& Design Journal, 1(3), 61-125.

Verderber, S., \& Realfuenzo, B. (2006). Innovation in hospice architecture. Taylor \& Francis.

Vischer, J. C. (2008). Towards a user-centred theory of the built environment. Building Research and Information, 36(3), 231-240.

Vischer, J. C. (2009). Applying knowledge on building performance: From evidence to intelligence. Intelligent Buildings International, 1(4), 239-248.

Worpole, K. (2009). Modern hospice design: The architecture of palliative care. Routledge. 